\title{
A ALTERIDADE DO SUJEITO NA PESQUISA EM LINGUÍSTICA APLICADA
}

\author{
SILVIO NUNES DA SILVA JÚNIOR ${ }^{1}$
}

Programa de Pós-Graduação em Linguística e Literatura

Universidade Federal de Alagoas

Faculdade de Letras - Avenida Lourival Melo Mota - Tabuleiro dos Martins

57083-410 - Maceió - AL - Brasil

junnyornunes@hotmail.com

\begin{abstract}
Resumo. Dentre os debates que circundam a área de estudos da Linguística Aplicada, me interessa, neste trabalho, os que focalizam o caráter reflexivo e alteritário em pesquisas qualitativas. Busco discutir sobre os movimentos de alteridade do sujeito nas ações de pesquisa em Linguística Aplicada. Numa perspectiva teórico-prática, apresento os movimentos de alteridade que circundaram uma pesquisa tomando como base o projeto de pesquisa inicial e a dissertação de mestrado na sua versão final. O estudo evidenciou que a autonomia do linguista aplicado em suas práticas revela alguns movimentos de alteridade, como: a alteridade do sujeito com a situação social, a alteridade do sujeito com o contexto e a alteridade do sujeito com os dados.
\end{abstract}

Palavras-chave: pesquisa qualitativa; sujeito; movimentos de alteridade.

\begin{abstract}
Among the debates surrounding the area of Applied Linguistics studies, I am interested in this work, those that focus on the reflective and alterative character in qualitative research. I seek to discuss the subject's otherness movements in research actions in Applied Linguistics. From a theoretical-practical perspective, I present the alterity movements that surrounded a research based on the initial research project and the master's dissertation in its final version. The study showed that the linguist's autonomy applied in his practices reveals some movements of otherness, such as: the subject's otherness with the social situation, the subject's otherness with the context and the subject's otherness with the data.
\end{abstract}

Keywords: qualitative research; subject; alterity movements.

\footnotetext{
${ }^{1}$ Doutorando e mestre em Linguística pelo Programa de Pós-graduação em Linguística e Literatura da Universidade Federal de Alagoas (PPGLL/UFAL). Licenciado em Letras/Português pela Universidade Estadual de Alagoas (UNEAL). Pesquisador do Grupo de Estudo das Narrativas Alagoanas (GENA/CNPq/UNEAL) e do Grupo de Estudos Discurso, Ensino e Aprendizagem de Línguas e Literaturas (GEDEALL/CNPq/UFAL). http://lattes.cnpq.br/0879864383265157
} 


\section{CONSIDERAÇÕES INICIAIS}

As problemáticas sociais são e sempre serão os lugares de encontro entre pesquisadores da área de estudos da Linguística Aplicada. $\mathrm{O}$ caráter reflexivo assumido por pesquisadores dessa área destaca cada vez mais a transdisciplinaridade que a envolve desde a década de 1990. Assim, a ação de pesquisa na Linguística Aplicada é, antes de tudo, um ato de resistência que confronta as determinações da ciência tradicional, formalizante e positivista por natureza. O pensamento para fora dessa caixa fechada e estanque acaba sendo alvo de julgamentos pré-concebidos acerca do que se faz, de como se formula e se trata os objetos de pesquisa na Linguística Aplicada. Ao tratar desse assunto, Leffa (2001) pontua que essa diversidade de críticas é fruto da compreensão de ciência como algo dentro de uma plataforma imóvel. A incompreensão surge quando a Linguística Aplicada assume a sua plataforma móvel e agrega variadas perspectivas teóricas e metodológicas em processos de aprendizagens e reaprendizagens.

Nessa dinâmica, a Linguística Aplicada se aproxima da Teoria Dialógica da Linguagem por ambas compartilharem a preocupação em estudar situadamente a prática social em busca de reflexões que provoquem de alguma maneira transformações sociais. Entretanto, ainda é latente a ausência de estudos que problematizem o papel do sujeito que formula, discute e age no desenvolvimento de pesquisas. A observação das práticas do pesquisador pode influenciar outros sujeitos a pensarem mais efetivamente nos seus papeis como integrantes do processo de pesquisa, enfatizando, de modo mais intenso, o compromisso da pesquisa em Linguística Aplicada mediante os avanços alcançados pelas/nas práticas sociais. Essa observação é povoada por diferentes concepções dialógicas, em que se destaca a de alteridade, pois é a partir da compreensão do discurso na vida que o sujeito está propício a construir mudanças nas suas construções identitárias.

Assim, entendo que a Teoria Dialógica da Linguagem, além de servir de pressuposto teórico para o desenvolvimento de análises de dados, é um construto significativo para repensarmos as concepções/posições de sujeitos, as quais são naturais na abordagem qualitativa. Diante disso, com este estudo, procuro discutir sobre os movimentos de alteridade do sujeito nas ações de pesquisa em Linguística Aplicada. $\mathrm{Na}$ análise que estou propondo neste artigo, utilizo alguns acontecimentos que direcionaram uma investigação a nível de mestrado desenvolvida no âmbito do Programa de Pósgraduação em Linguística e Literatura da Universidade Federal de Alagoas (PPGLL/UFAL), tomando como base o projeto de pesquisa inicial e a dissertação de mestrado em sua versão final. Para tanto, além das considerações iniciais e finais, o trabalho comporta os tópicos: Linguística Aplicada, contemporaneidade e vida social; língua/linguagem, discurso, responsividade e alteridade do sujeito; alteridade(s) em ações de pesquisa.

\section{LINGUÍSTICA APLICADA, CONTEMPORANEIDADE E VIDA SOCIAL}

Diversas obras foram publicadas após a segunda virada da Linguística Aplicada, que caracteriza a inscrição da área na perspectiva transdisciplinar que norteia as pesquisas mais atuais. Com essa diversidade de discussões teórico-metodológicas sobre os pressupostos que embasam as ações de pesquisa em Linguística Aplicada, torna-se complexa a tarefa de explorar as relações entre Linguística Aplicada, contemporaneidade 
e vida social. Por essa razão, nos limites deste tópico, estabeleço uma articulação entre as conceituações de Linguística Aplicada, focalizando a ação de pesquisa, a investigação nas ciências humanas na contemporaneidade e a necessária reflexão do sujeito sobre a vida e o mundo no processo de pesquisa.

Para compreender a ação de pesquisa em Linguística Aplicada e como ela se diferencia das práticas de pesquisa comuns às outras áreas, trago a noção de sujeito (de pesquisa) heterogêneo, a qual se distancia da concepção cartesiana de neutralidade do pesquisador, pressuposta pelo paradigma positivista. Moita Lopes entende que

\begin{abstract}
É necessário reteorizar o sujeito social em sua heterogeneidade, fluidez e mutações, atrelando a esse processo os imbricamentos de poder e desigualdade inerentes. Tradicionalmente, o sujeito da LA tem sido um ser sem gênero, raça e sexualidade. Ou, no máximo, tem sido construído com um gênero, raça e sexualidade fixos do qual não consegue escapar; com a linguagem refletindo o que ele é, ao invés de ser compreendida como um lugar de construção da vida social e, portanto, dele mesmo. (MOITA LOPES, 2009, p. 21)
\end{abstract}

Com o enfoque dado às práticas sociais, que são, fundamentalmente, diversificadas e mistas, a Linguística Aplicada exige do sujeito uma constituição fluida e descentralizada. Assim, não se pode pensar em padrões, regras ou modelos de pesquisa numa área de estudos que reflete e interpreta a vida social nos seus variados aspectos. A Linguística Aplicada é híbrida e mestiça (MOITA LOPES, 2006) por compreender que o contexto social jamais será único, até porque nele habitam sujeitos com os mais variados modos de interpretar o mundo. $\mathrm{O}$ pesquisador, com isso, não pode desenvolver sua investigação sem que se assuma como um sujeito imerso no ato de pesquisa, ou seja, não há como descrever e interpretar determinado contexto sem que se considere parte dele.

Nessa perspectiva, cada discurso carrega um conjunto de construções ideológicas que representam e materializam a singularidade do acontecimento social. Diferentemente de outras áreas, a Linguística Aplicada não parte de ideias prefixadas a respeito de algum tema, mas destaca a relevância de cada estudo mostrar seu diferencial a partir de novos acontecimentos. No que concerne ao aspecto de ineditismo cobrado pela ciência tradicional, o estudo em Linguística Aplicada é sempre inédito e isso se justifica, inicialmente, pela formação do pesquisador, a qual antecede a decisão de se fazer pesquisa, principalmente numa conjuntura em que os acontecimentos são cada vez mais emergentes. Por serem desenvolvidas em contextos situados, as pesquisas de Linguística Aplicada são sempre inéditas. De acordo com Fabrício (2006), vivencia-se uma época de mudança global de perspectivas e de avanços sociais, econômicos e tecnológicos, época em que convivem ideias paradoxais: racionalismo e irracionalismo, cientificismo e misticismo, humanismo e barbárie, intelectualismo e anti-intelectualismo. Tal panorama é responsável pela perda de referências explícitas que geram sujeitos em choque, em conflito e desorientados, devido ao colapso de seu sistema de crenças e valores.

O choque sociocultural mencionado por Fabrício (2006) indica a necessidade de, numa dada sociedade, dicotomias serem quebradas na busca por ações sociais reflexivas e situadas no ato de se fazer pesquisa. A diversidade de abordagens sobre as práticas sociais pode acabar gerando confusão na reflexão que o sujeito faz sobre si e sobre a vida social. O sistema que, mesmo podendo ser deslocado, é imposto aos sujeitos de modo 
bastante impulsivo, precisa, num curto período de tempo, ser absorvido por eles. $\mathrm{Na}$ maioria das vezes, essa absorção não vem acompanhada por uma reflexão sobre como o sistema atua na conjuntura social em que o sujeito se inscreve no cotidiano. Em articulação com a discussão proposta por Fabrício (2006), acredito que a necessidade de problematizar os sistemas que são encontrados no dia a dia constitui um processo de desaprendizagem (FABRÍCIO, 2006). Para a autora, a Linguística Aplicada é

Uma área de conhecimento que, suspeitando dos sentidos usuais, se coloca em movimento contínuo e autorreflexivo de deriva de si, sem destino fixo. Aposta, assim, nos descaminhos e na desaprendizagem de qualquer tipo de proposição axiomática como um refinamento do processo de conhecer [...] aquele que se realiza no trânsito por diferentes regimes de verdade e diferentes áreas disciplinares, desfamiliarizando os sentidos neles presentes e modificando a experiências da própria área de conhecimento na qual se insere (FABRÍCIO, 2006. p. 61).

A pesquisa social não traz consigo o caráter de ensinar, instruir ou passar determinado conjunto de conhecimentos anteriormente adquiridos e/ou produzidos por algum sujeito. Essa área de estudos abre espaço para aprendizagens conjuntas e contínuas, para desconstruir ideias estanques e buscar explicações para um fenômeno já estudado (ou não) em novos contextos. Sob essa ótica, a Linguística Aplicada não atua como um campo para se conhecer teorias, metodologias e práticas que pertencem a uma determinada área, mas, sim, de problematizar e interpretar a vida através de discursos e, assim, produzir, construir e compartilhar conhecimentos sobre algum fenômeno aplicado, podendo recorrer a articulações entre áreas próximas e/ou distantes. Sabendo que essas características nem sempre pertenceram à Linguística Aplicada, Moita Lopes depreende que essa

Agenda ética de investigação para a LA envolve crucialmente um processo de renarração ou redescrição da vida social como se apresenta, o que está diretamente relacionado à necessidade de compreendê-la. Isso é essencial para que o linguista aplicado possa situar seu trabalho no mundo, em vez de ser tragado por ele ao produzir conhecimento que não responda às questões contemporâneas em um mundo que não entende ou que vê como separado de si como pesquisador: a separação entre teoria e prática é o nó da questão. (MOITA LOPES, 2006, p. 90)

A reflexão de Moita Lopes (2006) traz à tona que a teoria não determina a ação do linguista aplicado. Na pesquisa na e sobre a prática social é possível que o pesquisador teorize a sua prática e, de acordo com os fatos observados, desconstrua ideias antes consideradas dominantes ou totalizantes. A esse respeito, Rampton (2006) destaca que a pesquisa em Linguística Aplicada vem se inserindo em três grupos distintos, os quais abrangem variadas situações de exclusão social que apresentam subsídios para interpretar e compreender outras questões. Esses grupos são os modos de expressão, interligados às questões de uso social de determinada língua, desmistificando padrões e sugerindo a compreensão de língua como prática social e não como um sistema inflexível e acabado; as organizações sociais, especialmente as regras fixadas a determinado contexto, apagando possibilidades de construir conhecimento em outras situações (ex.: na escola se 
aprendem conteúdos, em casa se descansa.); e as categorias sociais, no que diz respeito às condições de respeito e igualdade, isto é, de valorização do papel e do espaço do outro.

Diante disso, percebo que toda e qualquer problemática que assola as práticas sociais pode ser investigada sob a perspectiva da Linguística Aplicada, desde que os objetivos estabelecidos pelo pesquisador estejam à mercê da mudança, de novas ideias e problematizações. Em termos de pesquisa científica, a caracterização de Linguística Aplicada vinculada a uma posição de língua/linguagem como aspecto social, concreto e vivo (VOLÓCHINOV, 2017) pondera olhares mais amplos sobre as etapas que precisam ser seguidas. Assim, há uma desconstrução de bases de pesquisa, como pontuo a seguir:

- Objetivo/s: os objetivos precisam ser estabelecidos pelo pesquisador depois de uma observação inicial de um determinado contexto. O pesquisador, com as problematizações que são desenvolvidas ao longo do processo de produção de dados, reinventa seus objetivos e, por fim, pode comparar o que se pretendia com o que realmente foi efetuado;

- Hipóteses: o caráter processual da Linguística Aplicada e vivo da língua/linguagem não permite a formulação de hipóteses ${ }^{2}$, mas de questões/perguntas que possam nortear o processo de descrição e interpretação dos acontecimentos da pesquisa pelo investigador;

- Discussão teórica: diferentemente de outras áreas e linhas de pesquisa, a discussão teórica mantém uma relação de interdependência com o contexto de produção dos dados. Com isso, os dados são responsáveis pelo direcionamento teórico do estudo;

- Metodologia: a partir das condições propiciadas ao pesquisador, a metodologia vai focalizar o sujeito (ou os sujeitos) que será mais efetivamente observado e, a partir disso, vai se inserir em uma ou mais de uma vertente vinculada à abordagem qualitativa de pesquisa;

- Análise: por serem os dados decisivos para a construção teórica do trabalho, as análises baseiam-se numa perspectiva em que não há distância, no que compete à estruturação do trabalho, entre a teoria e a análise dos dados em Linguística Aplicada, pois, numa perspectiva interpretativa, os dados revelam até mesmo novas teorias que são instauradas pela pesquisa.

Nesse sentido, a dinâmica da pesquisa em Linguística Aplicada vai além dos padrões de pesquisa que norteiam investigações de base positivista, ou formalizante, e frisa possibilidades de a pesquisa problematizar práticas e causar transformações sociais. Acerca disso, Santos, Meneses e Nunes (2004, p. 21) entendem que

É insustentável a situação de, por exemplo, as ciências sociais continuarem a descrever e interpretar o mundo em função de teorias, de categorias e de metodologias desenvolvidas para lidar com as sociedades modernas do Norte, quando a maioria das sociedades não só apresenta características e dinâmicas históricas diferentes, como tem gerado as suas próprias formas de conhecimento das suas experiências

\footnotetext{
${ }^{2}$ A não-formulação de hipóteses é uma opção política da chamada Linguística Aplicada Dialógica. Em outros diferentes modos de compreender a Linguística Aplicada é comum que hipóteses sejam formuladas, a depender das denominações teóricas e metodológicas do pesquisador.
} 
sociais e históricas e produzido contribuições significativas para as ciências sociais, ainda que remetidas para as margens destas.

É nessa perspectiva que Santos, Meneses e Nunes (2004) defendem que a pesquisa acadêmica precisa considerar as vozes do sul, ou seja, as minorias sociais, os sujeitos em condições marginalizadas, para que, assim, possa-se obter resultados que alertem e clamem por transformação social em qualquer que seja o contexto. Pesquisar a sociedade é pensar em desmistificar ideias totalizantes e discriminatórias e produzir dados que demonstrem aspectos que careçam de mudança. Para o pesquisador, a pesquisa social, como a investigação em Linguística Aplicada em situações de exclusão, acarreta novas maneiras de refletir, interpretar e agir na vida social, pois é no ato de conhecer que o sujeito se coloca no papel do outro e compreende boa parte das significações sociais que o outro produz pelo discurso, que é dialógico.

O sujeito de pesquisa, e não só o pesquisador, pode produzir, no conjunto que compõe a sua formação, significações sociais até então não pensadas. Quando colocados em choque, os discursos propiciam uma diversidade de aprendizagens a partir de histórias, fatos, construções culturais etc. Tomadas essas afirmações, Santos (2000) considera que há anos se vive um processo de mudança paradigmática. Tal mudança é emergente porque ocorre nas diferentes práticas que os sujeitos estão incluídos, até porque essas práticas possuem interligação com outras, mesmo que não diretamente. Mudar paradigmas (conceitos, ideias, valores etc.) só é possível se as vozes que compõem determinado grupo problematizem os pontos concebidos como estáticos. A pesquisa, assim, pode ser um lugar de encontro entre essas vozes, uma vez que o caráter híbrido da sociedade muitas vezes impede interações importantes para o desenvolvimento de determinado conjunto social. Santos (2000, p. 42) complementa, ainda, que "o princípio da comunidade e a racionalidade estético-expressiva são as representações mais inacabadas da modernidade ocidental". Partindo desse princípio, os sujeitos podem caminhar para a emancipação humana da qual precisam para efetuarem ações que enfaticamente causem impactos positivos em suas situações de vivência.

Observo que as ciências sociais, em que, segundo Moita Lopes (2006), se inscreve a Linguística Aplicada ${ }^{3}$, carrega uma extensa obrigação de problematizar e agir nos diferentes aspectos da vida social. É preciso que se pense nos impactos que uma pesquisa pode causar e que se busquem subsídios para que as investigações sobre a sociedade provoquem as transformações mais abrangentes que podem promover. $\mathrm{O}$ caráter democrático, crítico e de desconstrução que a Linguística Aplicada defende acarreta um pensamento linguístico-social altamente vinculado à posição do outro no ato de pesquisa e na vida como um todo. Nesse sentido, não há como pensar numa área de reflexão sobre a linguagem sem que esta seja objeto de estudo e pressuposto para que o objeto seja estudado. Em outras palavras, a linguagem é a arena na qual a pesquisa é desenvolvida e, também, é objeto de estudo (oral ou escrito) da investigação.

Dentro da relação entre a Teoria Dialógica da Linguagem e a Linguística Aplicada, percebo a necessidade de se pensar a pesquisa em Linguística Aplicada dentro de fora das delimitações de objeto de pesquisa. O diálogo social e demais categorias

\footnotetext{
${ }^{3}$ Moita Lopes (1996, 2006), em ambas as obras deixa claro que, para ele, a Linguística Aplicada está mais inserida nas ciências sociais do que mesmo na Linguística, mesmo que, até os dias atuais, as agências de fomento e demais órgãos a coloque como área ou subárea da Linguística.
} 
podem ser discutidos através das próprias ações do pesquisador nas ciências sociais, uma vez que nenhuma temática é definida de qualquer maneira. O papel do pesquisador tem sua valia, pois é na reflexão inicial que ele faz do mundo, da vida social, que o estudo toma seus rumos mais curtos e mais extensos, a depender da situação. Nessa linha de pensamento, o tópico de discussão a seguir contempla algumas reflexões oriundas da Teoria Dialógica da Linguagem, numa interligação direta com o que foi aqui explanado.

\section{LÍNGUA/LINGUAGEM, DISCURSO, RESPONSIVIDADE E ALTERIDADE DO SUJEITO}

Pesquisas como as de Raimundo da Silva (2019), Gasparotto (2014), dentre outras, anunciam o foco dado em suas investigações à articulação entre a Teoria Dialógica da Linguagem e a Linguística Aplicada. Processos de ensino e aprendizagem e demais práticas sociais mediadas pela linguagem podem ser investigadas sob a ótica do dialogismo a partir de diferentes noções, em especial a de gênero do discurso (BAKHTIN, 2003), dada a alta visibilidade a essa temática por pesquisadores de ensino de língua portuguesa e de línguas estrangeiras. Entretanto, ainda são poucas as abordagens que se direcionam à ação do pesquisador como prática dialógica e, por consequência, discursiva, reflexiva, híbrida e ideológica, como o que objetivo discutir neste estudo. Para tanto, articulo, aqui, considerações sobre língua/linguagem, discurso, responsividade e alteridade do sujeito.

Diferentemente de vertentes de estudo da Linguística, a Teoria Dialógica da Linguagem, representada, principalmente, por estudiosos como Bakhtin e Volóchinov, acredita que a língua/linguagem se estabelece como construto social, concreto, dinâmico (BAKHTIN, 2003) e vivo (VOLÓCHINOV, 2017). Tal pensamento leva à compreensão de que o discurso não é um produto pronto e inflexível que medeia as atividades de linguagem. O discurso é dialógico por ser estabelecido no dia a dia do sujeito e, mesmo que se assemelhe a outras práticas discursivas, é único no momento da interação discursiva, pois interdepende da intenção e da situação histórico-social. Ao tratar dos gêneros do discurso, compreendidos como tipos relativamente estáveis de enunciados (BAKHTIN, 2003), percebo que a visão de Bakhtin (2003) se estende a toda e qualquer interação mediada pela linguagem. Com isso, não há como se pensar em gênero, nem em discurso, sem que se retome a natureza ideológica que ele carrega. Em outras palavras, a teoria dialógica defende que a prática discursiva é um ato e, por isso, é responsável.

A esse respeito, Bakhtin comenta que

O que subjaz à unidade de uma consciência responsável não é um princípio como ponto de partida, mas o fato de um real reconhecimento da participação própria de alguém no Ser-evento unitário, e esse fato não pode ser adequadamente expresso em termos teóricos; pode apenas ser descrito e participativamente experimentado. Aqui está o ponto de origem da ação responsável e de todas as categorias do dever concreto, único e necessário. Eu, também, existo [et ego sum] (em toda a plenitude emocional-volitiva, realizadora [postupochnaia] dessa afirmação) realmente - no todo, e assumo a obrigação de dizer esta palavra. Eu também participo do Ser de uma maneira única e irrepetível: eu ocupo um lugar no Ser único e irrepetível, um lugar que 
não pode ser tomado por ninguém mais e que é impenetrável a qualquer outra pessoa. No dado ponto único onde eu agora estou, ninguém jamais esteve no tempo único e no espaço único do Ser único. E é em torno deste ponto único que todo o Ser único se dispõe de um modo único e irrepetível. Aquilo que pode ser feito por mim não pode nunca ser feito por ninguém mais. A unicidade ou singularidade do Ser presente é forçadamente obrigatória. (BAKHTIN, 1993, p. 58, grifos do autor)

Como já pontuado, o discurso não pode ser reproduzido da mesma forma, uma vez que a compreensão do interlocutor é sempre nova, assim como a réplica que este pode dar em um dado momento na interação verbal. Considerando que é na linguagem que o ato discursivo se concebe, ele é responsável por se materializar como a produção de determinado sujeito numa prática social. A interação discursiva pode acarretar diferentes outras práticas mediadas pela linguagem. Todas as ações estimuladas pelo discurso interdependem do que Bakhtin (2003) denomina compreensão responsiva ativa. Para ele,

Toda compreensão plena real é ativamente responsiva e não é senão uma fase inicial preparatória da resposta (seja qual for a forma em que ela se dê). O próprio falante [enunciador] está determinado precisamente a essa compreensão ativamente responsiva: ele não espera uma compreensão passiva, por assim dizer, que apenas duble o seu pensamento em voz alheia, mas uma resposta, uma concordância, uma participação, uma objeção, uma execução, etc. (BAKHTIN, 2003, p. 272).

Nesse sentido, não há como, na interação discursiva, a compreensão não ser ativa. O ativismo da compreensão do sujeito é dado pela unicidade do ato da interação verbal. O silêncio ou qualquer manifestação do sujeito após a produção de um discurso pode ser entendido como compreensão responsiva ativa. Entretanto, existem graus de ativismo que diferenciam uma compreensão responsiva ativa da outra. Volóchinov (2017) entende que não existe discurso sem que, no diálogo social, exista a participação de dois sujeitos socialmente. O diálogo é social por estar sempre em sintonia com determinada prática, envolvendo temas variados. No ambiente institucional, por exemplo, o diálogo entre professor e alunos pode acarretar a construção de aprendizagens, uma vez que, mesmo ocupando posições hierárquicas distintas, ambos podem integrar a interação discursiva. A compreensão responsiva ativa, de acordo com Bakhtin (2003, p. 271-272), pode ter efeito imediato ou, a depender do contexto, efeito retardado. Para o filósofo,

É claro que nem sempre ocorre imediatamente a seguinte resposta em voz alta ao enunciado logo depois de pronunciado: a compreensão responsiva do ouvido (por exemplo, de uma ordem militar) pode realizar-se imediatamente na ação (o cumprimento da ordem ou comando entendidos e aceitos para execução), pode permanecer de quando em quando como compreensão responsiva silenciosa (alguns gêneros discursivos foram concebidos apenas para tal compreensão, como por exemplo os gêneros líricos), mas isso, por assim dizer, é uma compreensão responsiva de efeito retardado: cedo ou tarde o que foi ativamente entendido responde nos discursos subsequentes ou no comportamento do ouvinte (BAKHTIN, 2003, p. 271-272).

Nessa linha de pensamento, o discurso nem sempre é compreendido no momento em que a interação ocorre. Assim, nenhuma interação dá-se por finalizada na situação em 
que é efetuada. A resposta dada pelo interlocutor pode ser planejada e dada em um outro momento, provocando uma nova prática dialógica. Os acontecimentos de sala de aula, principalmente no que diz respeito à aprendizagem do sujeito, são objetos discursivos importantes para analisar esses fenômenos. A valorização do papel do outro e a possibilidade dada a ele de refletir sobre a linguagem dentro e fora da escola indicia o desenvolvimento de abordagens de ensino vinculadas à perspectiva dialógica. Por essa razão, a pesquisa em Linguística Aplicada critica as práticas ditas tradicionais de ensino pelo impedimento que acaba existindo no que concerne ao estímulo dado ao diálogo social em sala de aula (SILVA JÚNIOR; SANTANA, 2020; ZOZZOLI, 2016). Acredito, assim, que a ação pedagógica não pode ser limitada a transmissões conteudistas na busca por memorização. É preciso pensar, como as conceituações de Linguística Aplicada anunciam, na construção processual e reflexiva de conhecimentos linguístico-discursivos, pois "a concepção dialógica de compreensão responsiva ativa já seria necessária nas práticas de formação e constitui uma questão indispensável, caso contrário não se contempla o todo do processo" (ZOZZOLI, 2012, p. 163).

A partir das considerações de Zozzoli (2012), entendo que, em contextos escolares, a noção de compreensão responsiva ativa só pode ser um aspecto contribuinte para a construção efetiva de conhecimentos se os momentos de formação inicial e continuada favoreçam essa questão. Caso a formação do professor não esteja direcionada à compreensão de língua/linguagem como prática social e, assim, ao entendimento de que é no diálogo social que a prática de ensino se constrói num processo, é praticamente impossível que, em sala de aula, o professor possa ter a sensibilidade necessária para pensar no papel do outro e nas contribuições que a multiplicidade de vozes pode trazer para determinada prática social, como o ensino de determinada língua.

Nessa perspectiva, em articulação com a noção de sujeito heterogêneo, formulada por Moita Lopes (2009), é perceptível que nas práticas escolares essa heterogeneidade seja prezada na ação de pesquisa em Linguística Aplicada. Com isso, os sujeitos, no todo dialógico que é a linguagem, podem passar por processos de desconstruções de ideias e, como escreve Faraco (2009), por atravessamento de valores axiológicos. O caráter múltiplo em que se inscrevem as práticas sociais revela a necessidade de se considerar as vozes do sul (SANTOS, 2000) para a identificação do que Bakhtin (2003) nomeia relações dialógicas. Bakhtin (2003, p. 323) argumenta que

Onde não há palavra não há linguagem e não pode haver relações dialógicas; estas não podem existir entre objetos ou entre grandezas lógicas (conceitos, juízos, etc.). As relações dialógicas pressupõem linguagem, no entanto elas não existem no sistema da língua. Não são possíveis entre os elementos da língua. A especificidade das relações dialógicas requer um estudo especial.

Nesse contexto, a compreensão responsiva ativa é responsável pela efetivação das relações dialógicas em qualquer contexto de produção discursiva. As relações dialógicas se intercruzam na ampla dinâmica da linguagem e não podem ser identificadas em análises estruturais da língua, como análises sintáticas, fonético-fonológicas ou morfológicas. Para analisar as relações dialógicas é preciso que se tome a concepção de discurso trazida pela Teoria Dialógica da Linguagem. No plano responsivo ativo da interação verbal entre os sujeitos, não se acredita que um dado diálogo possa ser neutro a ponto de não contribuir de forma alguma para a formação dos seus participantes. Nesse 
sentido, o diálogo sempre vai favorecer um movimento que adensa superficialmente ou mais profundamente na identidade do sujeito. Para Bakhtin (2003), esse fenômeno que explicitamente articula a consciência psíquica ao mundo exterior (VOLÓCHINOV, 2017) é denominado alteridade, pois qualquer construção linguística estanque pode ser alterada no seio das relações dialógicas.

Para Volóchinov (2017), na reflexão sobre o discurso não se pensa em palavras pronunciadas ou escutadas em determinada situação de produção, mas, sim, em verdades ou mentiras, coisas boas ou más, importantes ou triviais, agradáveis ou desagradáveis, entre outras. Isso se justifica pelo fato de a palavra vir sempre carregada de ideologias, frutos de vivências com as vozes dos outros, ou seja, nos contatos do sujeito com a vida social. Segundo Bakhtin

Nossa fala, isto é, nossos enunciados (...) estão repletos de palavras dos outros. (Elas) introduzem sua própria expressividade, seu tom valorativo, que assimilamos, reestruturamos, modificamos. (...) Em todo o enunciado, contanto que o examinemos com apuro, (...) descobriremos as palavras do outro ocultas ou semi-ocultas, e com graus diferentes de alteridade. (BAKHTIN, 2003, p. 314),

Com base no pensamento bakhtiniano, acredito que qualquer relação dialógica pode ser estudada no discurso cotidiano. Entretanto, as análises dialógicas do discurso não seguem um padrão fixo que serve para o enquadramento de discursos. É necessária uma adaptação contextual, sócio-histórica e, sobretudo, ideológica, visto que cada discurso é produzido e analisado em situações distintas. Partindo desse pressuposto, depreendo que a alteridade que se dá na interação verbal oscila no diálogo social, assim como a compreensão responsiva ativa, até porque ambas as concepções dialógicas (responsividade e alteridade) estão interligadas em termos de discurso e de gênero do discurso.

Em qualquer que seja a ação social, é possível que se perceba como a interação discursiva provoca mudanças nos modos de compreender e agir no mundo. Bakhtin (2003) destaca que alguns desses aspectos ficam ocultos e outros semi-ocultos. O autor deixa de mencionar aspectos explícitos porque, no discurso, nada fica totalmente explicitado e carece sempre de uma reflexão cuidadosa acerca do que foi verbalmente produzido. $\mathrm{O}$ processo de alteridade na linguagem não corresponde a algo prédeterminado que o produtor do discurso pode direcionar num dado momento. Por ser dialógico, esse processo pode ser efetuado mediante diferentes reações e, conforme discute Bakhtin (2003), pode ser retardado para um outro momento da vida social.

De acordo com Jobim, Souza e Albuquerque (2012, p. 111), a “alteridade [...] não se limita à consciência da existência do outro, nem tampouco se reduz ao diferente, mas comporta também o estranhamento e o pertencimento. O outro é o lugar da busca de sentido", bem como de incompletude e de provisoriedade. A alteridade e a responsividade estão interligadas de modo bastante particular nas discussões empreendidas pelo chamado círculo de Bakhtin. Dessa maneira, o ato responsivo e, consequentemente, alteritário, é unívoco e promove movimentos contínuos de desconstruções de conhecimentos e de novas aprendizagens, o que se aproxima em grande escala das ações de pesquisa efetuadas na perspectiva híbrida, crítica e transdisciplinar da Linguística Aplicada. O dialogismo 
propicia que a compreensão de língua/linguagem do sujeito seja fragmentada e remetida à dinâmica mestiça da sociedade e das vozes que a constituem.

Diante das considerações apresentadas, percebo que os trabalhos que englobam as noções da Teoria Dialógica da Linguagem na Linguística Aplicada estão fortemente voltados a como os conceitos são evidenciados nas práticas discursivas, como mostram os estudos de Batista (2015), Raimundo da Silva (2019) e Gasparotto (2013). Nesse sentido, direciono este estudo às ações do pesquisador e, assim, à pesquisa em Linguística Aplicada como um espaço de alteridade.

\section{ALTERIDADE(S) EM AÇÕES DE PESQUISA}

Para a análise que estou propondo neste artigo, utilizo dois materiais que representam momentos de iniciação e finalização de uma investigação em nível de mestrado desenvolvida no âmbito do Programa de Pós-graduação em Linguística e Literatura da Universidade Federal de Alagoas (PPGLL/UFAL) e aprovada pelo Comitê de Ética em Pesquisa ${ }^{4}$ (CEP/UFAL) da mesma instituição, a saber: o projeto inicial do pesquisador e a dissertação de mestrado em sua versão final. A análise não focaliza o objeto de estudo que direcionou a pesquisa, mas, sim, os movimentos discursivos de alteridade do pesquisador nos processos de produção e análise dos dados.

Amorim (2001) compreende que a alteridade é constitutiva da produção de conhecimento. Nesse sentido, toda pesquisa precisa passar por movimentos alteritários para possibilitar a produção de conhecimentos nas variadas áreas de conhecimento. As ações de pesquisa em Linguística Aplicada, conforme indica Moita Lopes (2006), levam em consideração um sujeito heterogêneo que pode fragmentar seus modos de compreender a vida a partir de experiências dentro e fora das pesquisas nas ciências sociais. Assim, não se espera que o pesquisador termine seu processo de investigação sem que a sua constituição como sujeito tenha sido modificada de alguma forma. Na Análise Dialógica do Discurso (ADD), Sobral (2009) entende que o sujeito da linguagem não age sozinho e, por isso, assume várias posições-sujeito no transcorrer de suas práticas. Assim, o sujeito heterogêneo da Linguística Aplicada é semelhante ao sujeito dialógico, conceituado na ADD. Diante disso, ambas noções são relevantes para a discussão aqui empreendida.

A investigação que me serve de base neste estudo se destaca pelos diferentes momentos em que o pesquisador precisou problematizar algumas questões que se apresentaram no transcorrer de todo o processo, as quais se iniciaram antes mesmo da inserção deste no lócus de pesquisa. Os questionamentos que o pesquisador precisou lidar são relevantes para que movimentos de alteridade sejam identificados, considerando que é com o surgimento da problemática que o estudo ganha o seu caráter único dentro do cenário científico de determinado campo do saber.

O primeiro movimento de alteridade do sujeito-pesquisador partiu do princípio de que a proposta inicial do projeto era a de realizar observações etnográficas nas suas

\footnotetext{
${ }^{4}$ Projeto de pesquisa aprovado em 02 de fevereiro de 2018 pelo Comitê de Ética em Pesquisa da Universidade Federal de Alagoas (CEP/UFAL) sob o processo de número 75527317.0.0000.5013.
} 
práticas pedagógicas para identificar de que modo a produção oral era trabalhada nessas práticas. No entanto, uma problemática se destacou quando se partiu para o lócus: a situação profissional do pesquisador, que, na época, não era professor regente de nenhuma instituição de ensino. O movimento de alteridade foi dado no momento em que foi necessário recorrer a uma professora colaboradora que abrisse a sua sala de aula para o desenvolvimento da pesquisa, o que, alteritariamente, modificou o interesse (que passou a envolver não só o ensino, mas a formação de professores) e a direção metodológica da pesquisa (que passou a ser, também, colaborativa).

Estou denominando esse primeiro movimento como alteridade do sujeito com a situação social. A situação social revela aspectos nem sempre planejados pelo pesquisador, o que justifica a crítica apresentada neste trabalho em relação à formulação de hipóteses na pesquisa em Linguística Aplicada que adota os pressupostos da ADD. A situação em que o sujeito pesquisador esteve submetido levou a pesquisa a tomar rumos diferentes do que havia sido planejado no projeto de pesquisa. Tal movimento de alteridade entra em evidência quando se compara o objetivo geral no projeto de pesquisa e na dissertação de mestrado em sua versão final, como mostra o Quadro 1.

Quadro 1: Movimento de alteridade do sujeito com a situação social.

\begin{tabular}{|c|c|}
\hline Projeto de pesquisa & Dissertação de mestrado \\
\hline $\begin{array}{l}\text { Investigar como as práticas orais podem } \\
\text { aprimorar situações de ensino de língua } \\
\text { portuguesa no ensino fundamental. }\end{array}$ & $\begin{array}{l}\text { Investigar o processo de colaboração } \\
\text { didática de um pesquisador e uma } \\
\text { professora regente em aulas de língua } \\
\text { portuguesa no } 9^{\circ} \text { ano do ensino } \\
\text { fundamental, especialmente no que diz } \\
\text { respeito à sistematicidade da produção } \\
\text { oral. }\end{array}$ \\
\hline
\end{tabular}

Na comparação desenvolvida no Quadro 1, o sujeito pesquisador passou por um processo que Moita Lopes (2006) nomeia como renarração e redescrição da vida social. Nele, o pesquisador sonda a sua situação social e outros aspectos para que as suas reflexões e ações de pesquisa estejam em constante diálogo. Esse processo se articula com a atitude responsiva ativa, trazida por Bakhtin (2003), uma vez que o sujeito sempre produz uma atitude após a sua compreensão em diferentes momentos. Assim, o sujeito, em contexto de pesquisa em Linguística Aplicada, precisa estar ciente de que seus modos de pensar e agir podem ser fragmentados no decorrer da investigação.

No caso da alteridade do sujeito com a situação social, as fragmentações vêm antes de a pesquisa iniciar, dadas as diferentes características contextuais. Sob essa ótica, concordo com Ponzio (2011) quando o autor assinala que se está "diante do humanismo da alteridade, que considera que o fato primário da existência não é o 'si mesmo' nem o 'para si', mas o 'o outro"'. A reflexão e a ação de pesquisa devem estar entremeadas para que o contato consigo e com o outro possa provocar outros meios de compreender o mundo e, por consequência, a pesquisa. Nessa perspectiva, a alteridade do sujeito com a situação social reverbera a discussão proposta por Santos, Meneses e Nunes (2004) sobre a impossibilidade de uma pesquisa imbricada nas práticas sociais ser efetuada em função 
de teorias pré-determinadas. O movimento de alteridade dado pelo sujeito na reformulação da proposta de pesquisa mostra a autonomia que o linguista aplicado precisa ter para buscar e criar condições para o desenvolvimento reflexivo, dinâmico e processual de sua investigação, que, conforme explica Moita Lopes (2013), é fundamentalmente qualitativa.

Por ser interpretativista, a Linguística Aplicada estimula processos reflexivos do pesquisador numa ótica contínua, na qual, ao se inserir num dado espaço, o sujeito precisa moldar as condições que lhe são dadas e adaptá-las ao seu objeto de estudo. Nessa conjuntura, conceituo essa situação como uma alteridade do sujeito com o contexto. $\mathrm{Na}$ pesquisa que está servindo como base para esta análise, o pesquisador iniciou suas atividades de colaboração didática com uma professora de língua portuguesa no intuito de desenvolver a investigação em turmas de $6^{\circ}$ ano do ensino fundamental, uma vez que a objetivação girava também em torno do trabalho pedagógico efetuado com alunos recém-chegados ao segundo ciclo do ensino fundamental. No entanto, a professora que aceitou colaborar com a pesquisa não estava, naquele ano letivo, atuando em turmas de $6^{\mathrm{o}}$ ano.

O movimento de alteridade do sujeito com o contexto foi necessário, dada a realidade de diferentes instituições públicas que resistem na abertura de espaço para o desenvolvimento de pesquisas em sala de aula. Para evitar novas problemáticas que pudessem prejudicar o desvelar do estudo que estava sendo iniciado, foi questionado à professora colaboradora em qual turma a produção dos dados poderia ser realizada. A docente informou a possibilidade de trabalho pedagógico em uma turma do $9^{\circ}$ ano. Com isso, o foco de sujeitos colaboradores foi fragmentado num movimento de alteridade do sujeito com o contexto, como mostra o Quadro 2.

Quadro 2: Movimento de alteridade do sujeito com o contexto.

\begin{tabular}{|l|l|}
\hline \multicolumn{1}{|c|}{ Projeto de pesquisa } & \multicolumn{2}{|c|}{ Dissertação de mestrado } \\
\hline $\begin{array}{l}\text { Análise dos processos de aprendizagem de } \\
\text { alunos do } 6^{\circ} \text { ano, visando aprimorar os } \\
\text { conhecimentos linguísticos desses sujeitos } \\
\text { que estão iniciando o segundo ciclo do } \\
\text { ensino fundamental. }\end{array}$ & $\begin{array}{l}\text { aprendizagem de língua portuguesa de } \\
\text { alunos de um } 9^{\circ} \text { ano do ensino } \\
\text { para a formação continuada de uma } \\
\text { professora colaboradora. }\end{array}$ \\
\hline
\end{tabular}

O movimento ilustrado no Quadro 2 lembra a discussão de Fabrício (2006), na qual a autora destaca que a pesquisa em Linguística Aplicada está imersa em possibilidades de colapso em sistemas de crenças e valores. Nesse sentido, não há como prever se a investigação vai ser efetuada tal como propõe um projeto de pesquisa. $\mathrm{O}$ colapso não significa uma mudança drástica no processo, mas, sim, alterações, das mais breves às mais complexas, que impliquem adequações coerentes em estudos que contribuam mais efetivamente para diferentes práticas sociais. Assim, como afirma Moita Lopes (2009), a Linguística Aplicada atua como um espaço de reteorizar o sujeito social. Em outros termos, os dados de pesquisa, produzidos de diferentes formas, podem 
reteorizar conceitos, trazendo elementos que dão continuidade a determinada linha de estudo.

A exemplo disso, destaco o estudo de Zozzoli (2002), no qual a pesquisadora, por meio de dados de pesquisa em salas de aula de línguas maternas e estrangeiras, e com base na noção de compreensão responsiva ativa de Bakhtin (2003), cria a noção de produção responsiva ativa ${ }^{5}$. Nessa perspectiva, a reteorização do sujeito social (MOITA LOPES, 2009) permeia a alteridade do sujeito com o contexto, na maneira com que alguma especificidade da pesquisa é alterada e os dados propiciam a construção de outros subsídios para tratar determinado objeto de pesquisa. Para Moita Lopes (2009), a reteorização requer fluidez, além das mutações que são naturais no desenvolvimento de estudos situados no plano transdisciplinar. A linguagem atua, para o mesmo autor, como um lugar de construção da vida social. Nessa linha de pensamento, não há como pensar numa plataforma móvel (LEFFA, 2001), em pesquisas que estudam elementos intersubjetivos da existência humana, visto que, de acordo com Volóchinov (2017), em todo signo ideológico confrontam-se índices de valor contraditórios. Os valores entram em cheque e produzem novos e diversificados sentidos e efeitos de sentido.

Os dois movimentos de alteridade até aqui elencados: alteridade do sujeito com a situação social e alteridade do sujeito com o contexto, se interligam aos processos preliminares de construção de pesquisas em Linguística Aplicada. A partir das reflexões propiciadas por essas noções e retomando a posição de Rampton (2006), que destaca o compromisso da Linguística Aplicada de interpretar fenômenos sociais, alerto para um terceiro movimento de alteridade do sujeito, dessa vez remetendo ao processo de tratamento dos dados que, em variadas vezes, revela a necessidade de recorrer a novos subsídios que podem contribuir para o esmiuçar do objeto de pesquisa.

Após o processo de produção de dados realizado numa sala de aula de $9^{\circ}$ ano do ensino fundamental numa perspectiva de colaboração docente, partiu-se para as práticas de análise de dados, embasando-se no que Leffa (2001) denomina triangulação articulação de diferentes dados e fontes que, em conjunto, contribuem para a efetuação mais satisfatória da investigação processual. Dessa maneira, na pesquisa que me serve como pressuposto foram produzidos dados em forma de: gravações de áudio das aulas, produções de textos escritos, planos de aula e materiais audiovisuais produzidos pelos colaboradores. Entretanto, algo que se tornou de suma necessidade foi a investigação do documento que regulamenta o ensino de língua portuguesa na escola em que a pesquisa acabara de ser efetuada.

Com essa realidade, a professora colaboradora foi solicitada para disponibilizar algum material pelo qual as práticas de ensino de língua portuguesa estivessem embasadas na escola. Foi nesse momento que a docente enviou um plano anual de ensino que era subdividido em três blocos: estratégias, metas e conteúdos. De acordo com a análise do plano anual de ensino da escola, evidenciou-se que o plano de ensino:

\footnotetext{
${ }^{5}$ Se a compreensão responsiva ativa corresponde ao modo com que o sujeito da linguagem responde a um enunciado numa dada situação de interação discursiva, a produção responsiva ativa, de Zozzoli (2002), ocorre no momento em que o aluno produz um texto e, a partir do que o professor discute junto com ele num movimento interlocutivo, um novo texto é produzido.
} 
- carecia de uma mudança conceitual no que concerne ao ensino, à aprendizagem, à língua e à literatura;

- precisava se adequar a uma perspectiva processual e articulatória de objetos de ensino de língua portuguesa.

Diante disso, a análise dos dados girou em torno dos resultados dessa análise para que se mostrasse como a investigação qualitativa e processual em Linguística Aplicada pode promover situações de ensino e aprendizagem de língua portuguesa mais adequadas para a construção de conhecimentos linguístico-discursivos. Assim, acredito que esse processo revela uma alteridade do sujeito com os dados. Tal processo de alteridade parte da necessária mudança paradigmática de que trata Santos (2000), pois a autonomia do sujeito no desenvolvimento da pesquisa o faz transformar contextos em busca de práticas sociais mais significativas, a exemplo das que ocorrem em contextos de ensino e aprendizagem de língua portuguesa. Nesse sentido, destaco a importância de antes de se iniciar um processo de análise, o tratamento e a observação geral dos dados é essencial para que se determine quais dados são mais favoráveis para a exposição na investigação, bem como para que se busquem mais dados, caso necessário.

\section{CONSIDERAÇÕES FINAIS}

Este trabalho procurou direcionar os pressupostos da Teoria Dialógica da Linguagem à caracterização e às ações de pesquisa na área de estudos da Linguística Aplicada, de modo a ilustrar possíveis movimentos de alteridade que são revelados nos processos de investigação processual e transdisciplinar. As reflexões apresentadas interligam duas concepções de sujeito: a de sujeito heterogêneo, formulada por Moita Lopes (2009), e a de sujeito dialógico e alteritário, empreendida a partir das discussões de Bakhtin (2003), Volóchinov (2017), dentre outros. O caráter múltiplo, híbrido e plástico das práticas sociais alerta para as diferentes possibilidades de o sujeito se reinventar e propiciar mudanças, locais e globais, em suas mais diversas ações de pesquisa.

Assim, fazer pesquisa é um ato responsável (BAKHTIN, 1993) pelo qual o pesquisador destaca suas posturas valorativas acerca de diferentes fenômenos. Essa nãoneutralidade do pesquisador, questionada por vertentes de estudo imbricadas no paradigma positivista, representa a necessária autonomia do pesquisador que formula um objeto e entra em campo para problematizá-lo e criar encaminhamentos para suas inquietações. A pesquisa em Linguística Aplicada não se propõe a constituir verdades estanques sobre temas diversos. Ela é uma arena alteritária que, nos termos de Moita Lopes $(2009,2006)$, permite a fluidez e a renarração de acontecimentos nunca previstos.

Ressalto que as ponderações trazidas neste estudo não são estancadas num único modo de entender os processos de pesquisa. Nesse sentido, os movimentos de alteridade perceptíveis na análise exposta não ocorrem em todas as investigações, dada a unicidade de cada objeto de pesquisa, acompanhado pela situação social, o contexto, os sujeitos etc. Dessa maneira, espero que este trabalho contribua para a expansão dos debates sobre a plasticidade das abordagens qualitativas de pesquisa, em especial as que se insiram na área de estudos da Linguística Aplicada. 


\section{REFERÊNCIAS}

AMORIM, M. O pesquisador e seu outro: Bakhtin nas Ciências Humanas. São Paulo: Musa, 2001.

BAKHTIN, M. M. Estética da criação verbal. Trad. P. Bezerra. 4. ed. São Paulo: Martins Fontes, 2003.

BAKHTIN, M. M. Para uma filosofia do ato. Trad. Carlos Alberto Faraco e Cristovão Tezza. Austin: University of Texas Press, 1993.

BATISTA, S. F. Reflexões sobre a compreensão responsiva ativa de alunos de EJA: um olhar a partir de práticas de letramento. Dissertação (Mestrado em Linguística), Faculdade de Letras, Universidade Federal de Alagoas, 2015.

FABRICIO, B. F. Linguística aplicada como espaço de desaprendizagem: redescrições em curso. In: MOITA LOPES, L. P (Org.) Por uma linguística aplicada indisciplinar. São Paulo: Parábola, 2006, p. 45-63.

FARACO, C. A. Linguagem \& Diálogo: as ideias linguísticas do círculo de Bakhtin. São Paulo: Parábola Editorial, 2009.

GASPAROTTO, D. M. O trabalho colaborativo em práticas de revisão e reescrita de textos em séries finais do ensino fundamental I. Dissertação (Mestrado em Letras), Universidade Estadual de Maringá, 2014.

JOBIM E SOUZA, S; ALBUQUERQUE, E. D. P. E. A pesquisa em ciências humanas: uma leitura bakhtiniana. Bakhtiniana - Revista de Estudos do Discurso, v. 7, p. 109$122,2012$.

LEFFA, V. J. A linguística aplicada e seu compromisso com a sociedade. In: Congresso Brasileiro de Linguística Aplicada, v. 6, Belo Horizonte, 2001. Não publicado.

MOITA LOPES, Introdução: Fotografias da Linguística Aplicada brasileira na modernidade recente: contextos escolares. In: MOITA LOPES, L. P (Org.) Linguística Aplicada na Modernidade Recente: Festschrift para Antonieta Celani. São Paulo: Parábola, 2013, p. 15-37.

MOITA LOPES, L. P. Da aplicação linguística à Linguística Aplicada Indisciplinar. In: PEREIRA, R. C; ROCA, P (Org.) Linguística Aplicada: um caminho com diferentes acessos. São Paulo: Contexto, 2009.

MOITA LOPES, L. P. Linguística aplicada e vida contemporânea: problematização dos construtos que têm orientado a pesquisa. In: MOITA LOPES, L. P (Org.) Por uma linguística aplicada indisciplinar. São Paulo: Parábola, 2006.

PONZIO, A. A revolução bakhtiniana. São Paulo: Contexto, 2011.

RAIMUNDO DA SILVA, F. Práticas docentes na sala de aula de língua portuguesa: uma articulação entre os gêneros escolares e as atividades de letramento literário num trabalho colaborativo. Dissertação (Mestrado em Linguística), Faculdade de Letras, Universidade Federal de Alagoas, 2019.

RAMPTON, B. Continuidade e mudança nas visões de sociedade em linguística aplicada. In: MOITA LOPES, L. P (Org.). Por uma linguística aplicada indisciplinar. São Paulo SP: Parábola Editorial, 2006, p. 109-128.

SANTOS, B. S. A crítica da razão indolente: contra o desperdício da experiência. São Paulo: Cortez, 2000.

SANTOS, B; MENESES, M. P; NUNES. J. A. Introdução: para ampliar o cânone da ciência: a diversidade epistemológica do mundo. In: SANTOS, B; MENESES, M. P; NUNES. J. A (Orgs.) Semear outras soluções: os caminhos da biodiversidade e dos conhecimentos rivais. Porto: Afrontamento, 2004. 
SILVA JÚNIOR, S. N; SANTANA, W. K. F. Abordagem dialógica no ensino de língua portuguesa: táticas para se desviar do método formal. Humanidades \& Inovação, v. 7, p. 284-293, 2020.

SOBRAL, A. Do dialogismo ao gênero: as bases do pensamento do Círculo de Bakhtin. Campinas, São Paulo: Mercado de Letras, 2009.

VOLÓCHINOV, V. Marxismo e filosofia da linguagem: Problemas fundamentais do método sociológico na ciência da linguagem. Trad. Sheila Grillo e Ekaterina Vólkova Américo. São Paulo: Editora 34, 2017.

ZOZZOLI, R. M. D. Diálogo social: cruzamentos discursivos a partir de um enunciadoacontecimento-tema. In: RODRIGUES, R. H; ACOSTA-PEREIRA, R. (Orgs.) Estudos dialógicos da linguagem e pesquisas em Linguística Aplicada. São Carlos, SP: Pedro João Editores, 2016, p. 109-128.

ZOZZOLI, R. M. D. A noção de compreensão responsiva ativa no ensino e na aprendizagem. Bakhtiniana: Revista de Estudos do Discurso, v. 7, p. 253-269, 2012.

ZOZZOLI, R. M. D. Produção e autonomia relativa na aprendizagem de línguas. In: LEFFA, Vilson (Org.) Pesquisa em linguística Aplicada Temas e métodos. Pelotas: EDUCAT, 2006, p. 105-143.

ZOZZOLI, R. M. D. Compreensão e produção responsivas ativas: indícios nas produções dos alunos. In: ZOZZOLI, R. M. D (Org.). Ler e Produzir: Discurso, texto e formação do sujeito leitor/produtor. Maceió: EDUFAL, 2002, p. 17-31.

Artigo recebido em: jul. de 2020.

Aprovado e revisado em: out. de 2020.

Publicado em: dez. de 2020.

Para citar este texto:

SILVA JÚNIOR, Silvio Nunes da. A Alteridade do Sujeito na Pesquisa em Linguística Aplicada. Entremeios [Revista de Estudos do Discurso, ISSN 2179-3514, on-line, www.entremeios.inf.br], Seção Estudos, Programa de Pós-Graduação em Ciências da Linguagem (PPGCL), Universidade do Vale do Sapucaí (UNIVÁS), Pouso Alegre (MG), vol. 22, p. 154-170, jul. - dez. 2020.

DOI: http://dx.doi.org/10.20337/ISSN2179-3514revistaENTREMEIOSvol22pagina154a170 